\title{
Plasma-Based Graphene Functionalization in Glow Discharge
}

\author{
X. Fang, J. Donahue, A. Shashurin, M. Keidar \\ Department of Mechanical \& Aerospace Engineering, The George Washington University, Washington DC, USA \\ Email: xiuqifang@gwu.edu, keidar@gwu.edu
}

Received 11 November 2014; accepted 4 December 2014; published 13 January 2015

Copyright (C) 2015 by authors and Scientific Research Publishing Inc.

This work is licensed under the Creative Commons Attribution International License (CC BY). http://creativecommons.org/licenses/by/4.0/

c) (i) Open Access

\begin{abstract}
Glow discharge was utilized to add oxygen functional groups to the graphene platelets sample produced in chemical exfoliation synthesis. It was concluded based on Raman spectra that the graphene sample treated with the glow discharge preserves specific graphene features while no transformation to amorphous carbon is happening. SEM and EDS results indicated the increases of oxygen content in the graphene sample after the exposure to the glow discharge. Raman spectra also support the fact that the graphene platelets have been decorated with oxygen as the result of the glow discharge treatment.
\end{abstract}

\section{Keywords}

\section{Graphene, Functionalization, Plasma-Based}

\section{Introduction}

Graphene is a flat, atomic-scale, honeycomb lattice [1], which is made of carbon atoms with a flat hexagonal atomic structure [2]. It is the world's first 2D material which extends only in length and width. This gives graphene a set of unique properties which has caught a lot of researcher's attentions [3]. It can dramatically improve the thermal and electrical conductivity of the medium it is added to, and significantly increases strength [4]. However, graphene is inherently inert and it does not always bond properly with the matrix on its own. Instead, graphene flakes tend to agglomerate resulting in its non-uniform distribution in final composite. In order to prevent this, functional groups must be added to the graphene [5] [6]. Other applications requiring graphene functionalization include membrane seperation and dehydration of organic or water mixture [7]-[9], etc. Ultra thin Graphene oxide membrane separation realizes high-flux, high-sensitivity mixture separation at low energy cost. Pristine multi-layered graphene oxide coated onto a thin film nano-fibrous composite (TFNC) mat forms a high flux membrane for organic or water dehydration. This is because once oxygen is added, there will be 
breaking of C-C bonds and releasing of $\mathrm{C}$ atoms, introducing defects; and oxygen groups can swell the interlayerspacing.

There are several methods to functionalize graphene and the most widely utilized is chemical functionalization [11]. This method is accompanied with numbers of disadvantages such as utilization and production of non-environmental friendly chemicals as well as adding an extra step to the synthesis process [12]. Another approach is to use plasma-based functionalization [13], which is benefited by increasing reactivity of the species. In addition, plasma-based functionalization enables functionalization as part of the synthesis process and it is also environmentally friendly. Different types of discharges such as microwave-excited surface-wave plasma [14], DC, RF plasmas were used to functionalize nanostructures [15]. SWCNTs were successfully functionalized with F, NH [16] [17], etc. In addition, the advantages of the plasma-based functionalization compared to wet chemical reactions were concluded. Other methods of graphene functionalization include ultraviolet oxidative treatment [18], ozone treatment [19]-[21], and photochemical oxidation [22].

However, there was no significant research done on plasma-based graphene functionalization. This work is focused on studying the benefits of glow discharge utilization for decorating graphene with oxygen functional groups (see Figure 1).

\section{Experimental Setup and Procedure}

The experiment was conducted inside a stainless steel chamber $(45 \mathrm{~cm}$ in diameter and $64 \mathrm{~cm}$ in length) pumped with mechanical pump to the residual air pressure of about $10^{-1}$ torr. A piece of copper wire with the diameter of $0.3 \mathrm{~mm}$ was used as the substrate and a little pitch of graphene flakes prepared by chemical exfoliation method (N006-P Polar Graphene Powder by Angstron Materials Inc) was placed on the substrate. Adjustable AC voltage up to $\sim 550 \mathrm{~V}$ was applied to the copper substrate with respect to chamber walls as shown schematically in Figure 2.

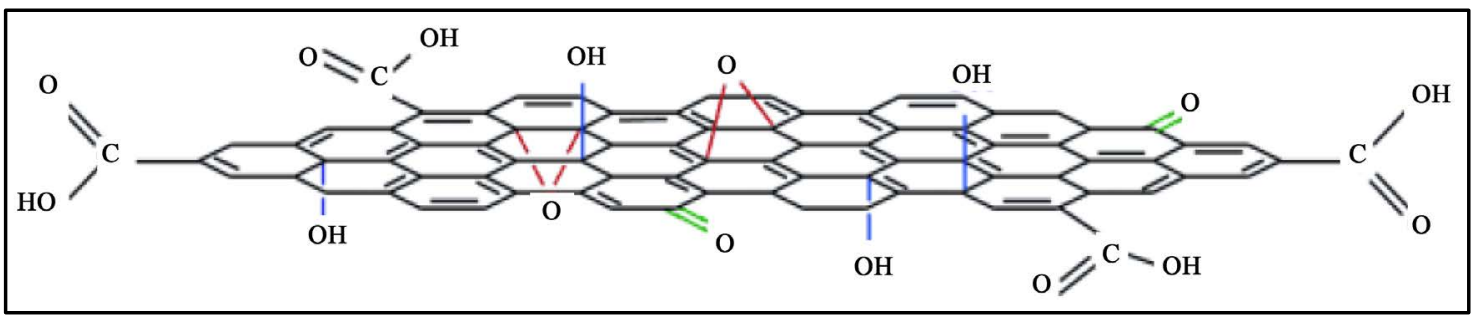

Figure 1. Graphene functionalized with $\mathrm{O}$ and $\mathrm{OH}$ groups [10].

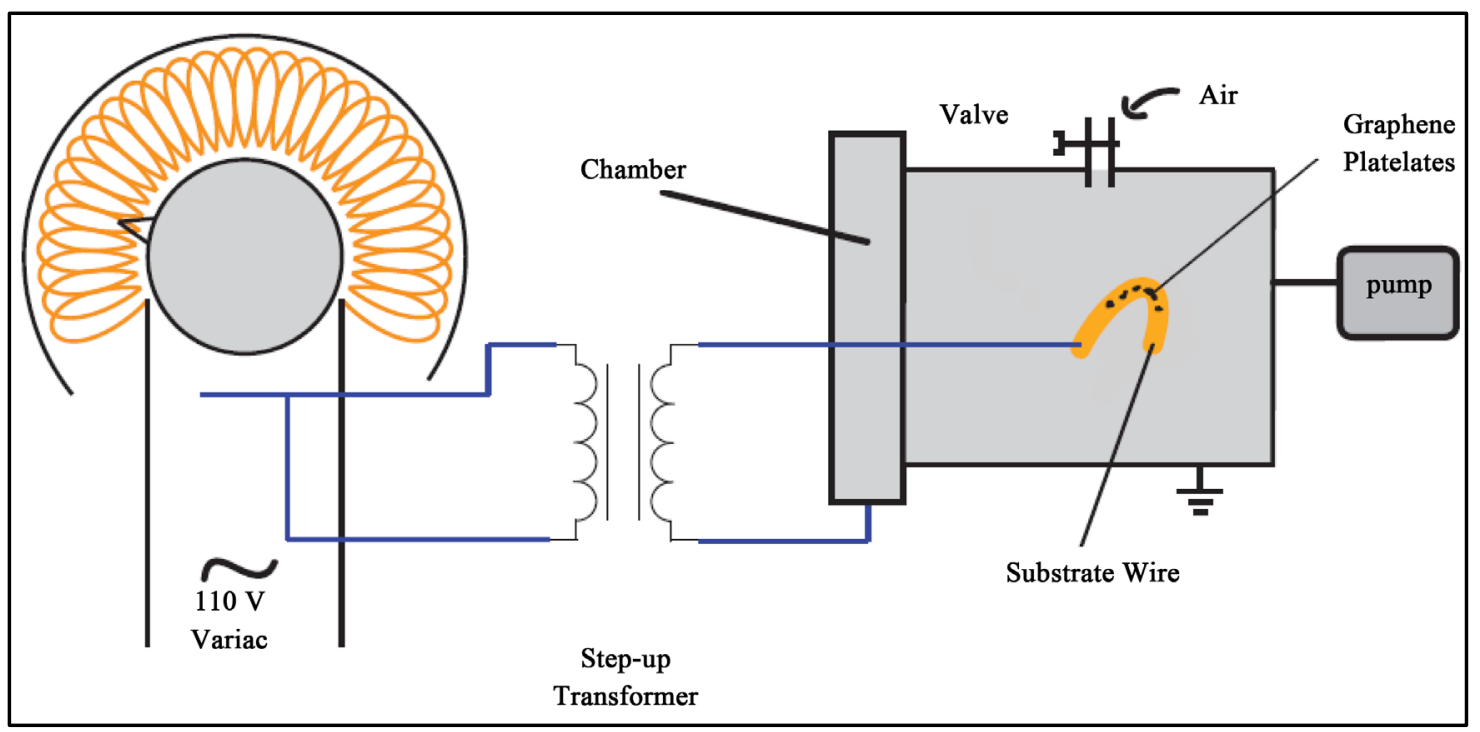

Figure 2. Experimental setup. 
The glow discharge of alternative current was ignited when amplitude of the applied AC voltage exceeds U $320 \mathrm{~V}$ [23]. The experiments were conducted at $\mathrm{U} \sim 476 \mathrm{~V}$ and exposure time was $90 \mathrm{~s}$. The glow discharge was concentrated around the substrate with graphene as shown in Figure 3.

The samples were characterized of using SIGMA VP-02-44 SEM equipped with OXFORD INCA x-act ADD0048 EDS and Horiba LabRAM Raman HR 800 spectrometer. Five randomly chosen points on the each sample were observed for averaging.

\section{Results and Discussions}

SEM images of treated and untreated samples are shown in Figure 4. No changes of morphology in the samples after the treatment were found. EDS results are shown in Table 1. It was observed that the average oxygen weight content (averaged over 5 randomly chosen points) was $2.31 \%$ before the exposure. After exposure to the glow discharge, the oxygen percentage rose to $4.74 \%$ which is an increase by $105.2 \%$. The admixture of copper in the samples was found to be less than $1 \%$.

As a next step it was determined using Raman Spectrometer whether flakes treated in plasma are still graphene, as opposed to amorphous carbon. This characterization procedure was performed with a Horiba RAMAN spectrum at room temperature. Figures 5(a)-(c) show Raman spectra of untreated and treated graphene sample. Three intense features D, G, G' peaks could be observed along the spectra at around $1355 \mathrm{~cm}^{-1}, 1575 \mathrm{~cm}^{-1}$ and $2700 \mathrm{~cm}^{-1}$. The D peak is associated with the amount of defects in sp2 bonds [24] and G peak is related to doubly degenerate E2g mode [25]-[27]. G' peak has nothing to do with G peak while its shape could be used to determine the number of layers of the graphene flakes. It can be seen the spectra for both treated and untreated flakes

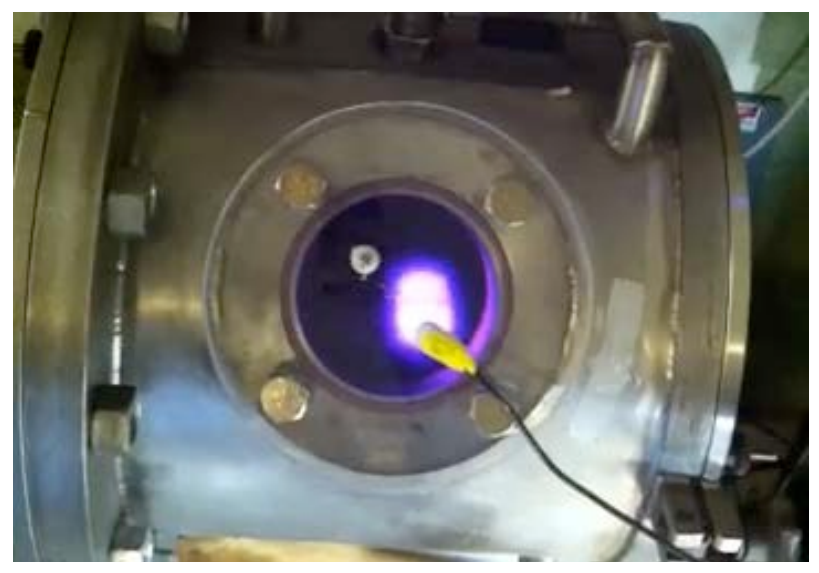

Figure 3. Glow discharge generated between two electrodes.
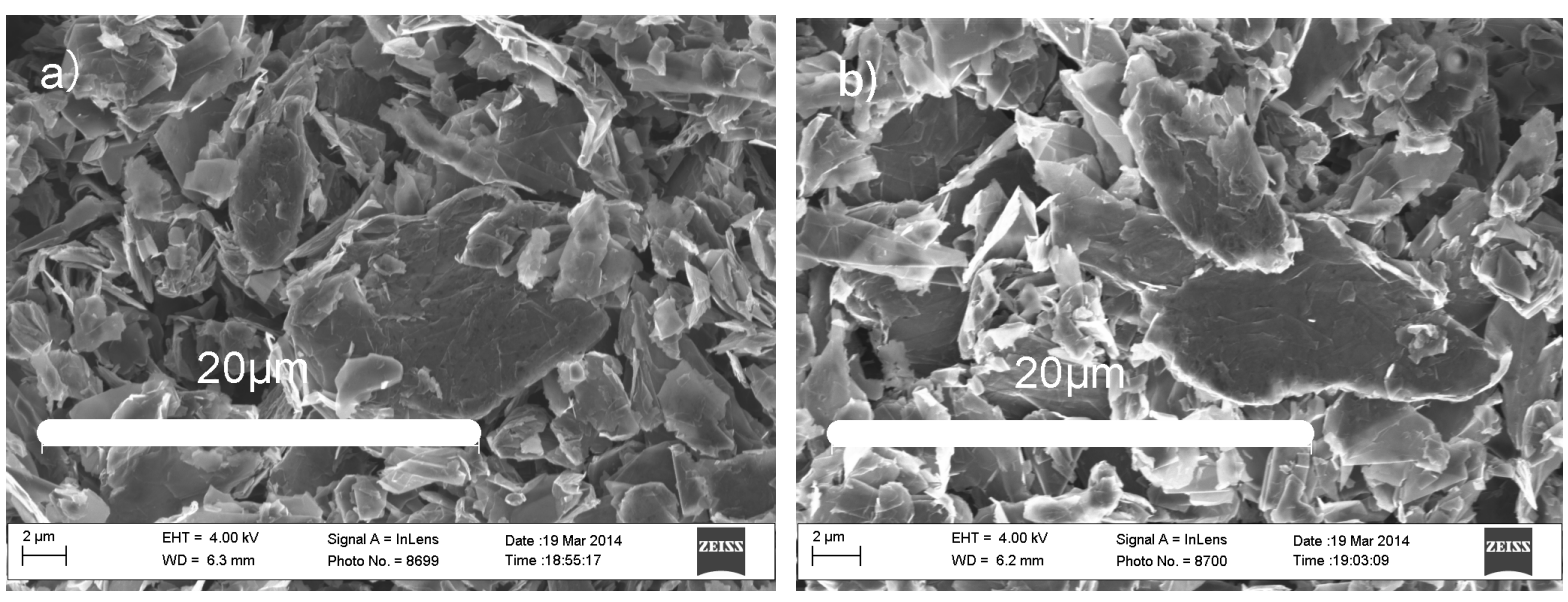

Figure 4. SEM images of N006-P Polar Graphene Powder which were observed under EDS (a) before and (b) after the exposure to the glow discharge. 


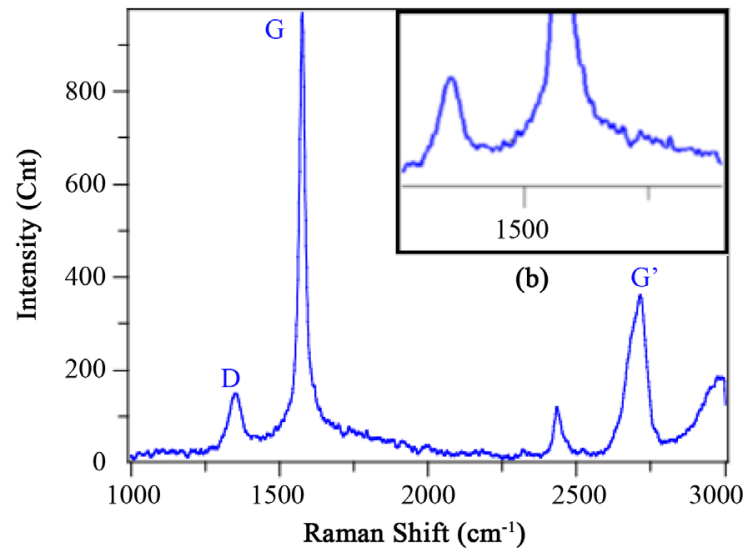

(a)

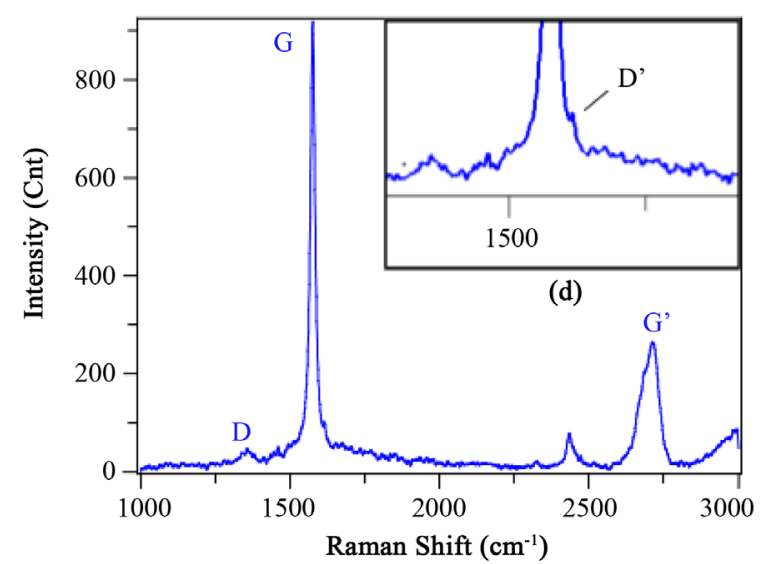

(c)

Figure 5. RAMAN spectra of (a)-(b) untreated N006-P Polar Graphene Powder and (c)-(d) plasma-treated N006-P Polar Graphene Powder.

Table 1. EDS material weight percentage of carbon and oxygen before and after exposure to the glow discharge.

\begin{tabular}{ccccccc}
\hline Weight\% & Element & Point 1 & Point 2 & Point 3 & Point 4 & Point 5 \\
\hline \multirow{2}{*}{ Before Exposure } & Carbon & $97.82 \%$ & $97.36 \%$ & $97.16 \%$ & $97.80 \%$ & $98.31 \%$ \\
& Oxygen & $2.18 \%$ & $2.64 \%$ & $2.84 \%$ & $2.20 \%$ & $96 \%$ \\
\multirow{2}{*}{ After Exposure } & Carbon & $94.50 \%$ & $93.63 \%$ & $96.82 \%$ & $96.14 \%$ & $3.86 \%$ \\
& Oxygen & $5.50 \%$ & $6.37 \%$ & $3.18 \%$ & $4.79 \%$ \\
\hline
\end{tabular}

were similar, and the ratio of $\mathrm{I}\left(\mathrm{G}^{\prime}\right) / \mathrm{I}(\mathrm{G})$ still remains 0.5 .

The main difference on the Raman spectra was presence of small D' peak on the plasma treated sample as shown on the zoomed to the range $1250-1700 \mathrm{~cm}^{-1}$ spectra shown in Figure 5(d). After the employment of the glow discharge, one can see that averaging of many RAMAN spectra indicate presence of small D' peak on treated sample. Presence of D' is indicator of graphene oxide according to Baraket et al. [28].

From the results above, one could tell there is a significant increase of oxygen content after the exposure to the glow discharge, while the graphene flake structure did not undergo significant change. After determining the elemental makeup of the graphene structure.

Future experiments will have to address influence of exposure duration and discharge voltage on the efficiency of functionalization and extend characterization of the functionalized graphene (e.g. XPS, XRD, AFM etc.).

\section{Summary}

We have shown that plasma-based glow discharge technique can be used for oxygen functionalization of graphene platelets. It is important to point out that the graphene sample did not changed into amorphous carbon after the exposure. SEM, EDS and Raman diagnostics inform about effective oxygen functionalization. Oxygen content was increased by factor of 2 after plasma exposure of 90 seconds. In addition, Raman spectra show presence of small D’ peak, which also indicates elevated presence of oxygen in the plasma treated sample. More detailed investigation of treatment conditions (voltage, time) is required in future in order to improve controllability of the glow discharge graphene modification.

\section{Acknowledgements}

Authors would like to acknowledge support from the National Science Foundation (EAGER: Exploring plasma mechanism of synthesis of graphene in arc discharge, NSF Award No. 1249213). This work was supported in part by the US Department of Energy, Office of Science, Basic Energy Science.

\section{References}

[1] Allen, M.J., Tung, V.C. and Kaner, R.B. (2009) Honeycomb Carbon: A Review of Graphene. Chemical Reviews, 110, 
132-145. http://dx.doi.org/10.1021/cr900070d

[2] Choi, W., Lahiri, I., Seelaboyina, R. and Kang, Y.S. (2010) Synthesis of Graphene and Its Applications: A Review. Critical Reviews in Solid State and Materials Sciences, 35, 52-71. http://dx.doi.org/10.1080/10408430903505036

[3] Geim, A.K. and Novoselov, K.S. (2007) The Rise of Graphene. Nature Materials, 6, 183-191. http://dx.doi.org/10.1038/nmat1849

[4] Baxendale, M. (2003) The Physics and Applications of Carbon Nanotubes. Journal of Materials Science: Materials in Electronics, 14, 657-659. http://dx.doi.org/10.1023/A:1026158432563

[5] Zhu, Y., Murali, S., Cai, W., Li, X., Juk, J.K., Potts, J.R. and Ruoff, R.S. (2010) Graphene and Graphene Oxide: Synthesis, Properties, and Applications. Advanced Materials, 22, 3906-3924. http://dx.doi.org/10.1002/adma.201001068

[6] Loh, K.P., Bao, Q., Eda, G. and Chowalla, M. (2010) Graphene Oxide as a Chemically Tunable Platform for Optical Applications. Nature Chemistry, 2, 1015-1024. http://dx.doi.org/10.1038/nchem.907

[7] Li, H., Song, Z., Zhang, X., et al. (2013) Ultrathin, Molecular-Sieving Graphene Oxide Membranes for Selective Hydrogen Separation. Science, 342, 95-98. http://dx.doi.org/10.1126/science.1236686

[8] Kim, H.W., Yoon, H.W., Yoon, S.M., Yoo, B.M., Ahn, B.K., Cho, Y.H. and Park, H.B. (2013) Selective Gas Transport through Few-Layered Graphene and Graphene Oxide Membranes. Science, 342, 91-95. http://dx.doi.org/10.1126/science.1236098

[9] Yeh, T.M., Wang, Z., Mahajan, D., Hsiao, B.S. and Chu, B. (2013) High Flux Ethanol Dehydration Using Nanofibrous Membranes Containing Graphene Oxide Barrier Layers. Journal of Materials Chemistry A, 1, 12998-13003. http://dx.doi.org/10.1039/c3ta12480k

[10] Haubner, K., Murawski, J., Olk, P., Eng, L. M., Ziegler, C., Adolphi, B. and Jaehne, E. (2010) The Route to Functional Graphene Oxide. ChemPhysChem, 11, 2131-2139. http://dx.doi.org/10.1002/cphc.201000132

[11] Boukhvalov, D.W. and Katsnelson, M.I. (2009) Chemical Functionalization of Graphene. Journal of Physics: Condensed Matter, 21, Article ID: 344205. http://dx.doi.org/10.1088/0953-8984/21/34/344205

[12] Boukhvalov, D.W. and Katsnelson, M.I. (2008) Chemical Functionalization of Graphene with Defects. Nano Letters, 8, 4373-4379. http://dx.doi.org/10.1021/nl802234n

[13] Keidar, M. and Beilis, I. (2013) Plasma Engineering: Applications from Aerospace to Bio and Nanotechnology. Academic Press, Waltham.

[14] Chen, C., Liang, B., Ogino, A., Wang, X. and Nagatsu, M. (2009) Oxygen Functionalization of Multiwall Carbon Nanotubes by Microwave-Excited Surface-Wave Plasma Treatment. The Journal of Physical Chemistry C, 113, 76597665. http://dx.doi.org/10.1021/jp9012015

[15] Khare, B., Wilhite, P., Tran, B., Teixeira, E., Fresquez, K., Mvondo, D.N., Bauschlicher, C. and Meyyappan, M. (2005) Functionalization of Carbon Nanotubes via Nitrogen Glow Discharge. The Journal of Physical Chemistry B, 109, 23466-23472. http://dx.doi.org/10.1021/jp0537254

[16] Khare, B.N., Meyyappan, M., Cassell, A.M., Nguyen, C.V. and Han, J. (2002) Functionalization of Carbon Nanotubes Using Atomic Hydrogen from a Glow Discharge. Nano Letters, 2, 73-77. http://dx.doi.org/10.1021/nl015646j

[17] Khare, B.N., Wilhite, P., Quinn, R.C., Chen, B., Schingler, R.H., Tran, B., Meyyappan, M., et al. (2004) Functionalization of Carbon Nanotubes by Ammonia Glow-Discharge: Experiments and Modeling. The Journal of Physical Chemistry B, 108, 8166-8172. http://dx.doi.org/10.1021/jp049359q

[18] Li, H., Huang, Y., Mao, Y., Xu, W.L., Ploehn, H.J. and Yu, M. (2014) Tuning the Underwater Oleophobicity of Graphene Oxide Coatings via UV Irradiation. Chemical Communications, 50, 9849-9851. http://dx.doi.org/10.1039/C4CC03940H

[19] Huh, S., Park, J., Kim, Y.S., Kim, K.S., Hong, B.H. and Nam, J.M. (2011) UV/Ozone-Oxidized Large-Scale Graphene Platform with Large Chemical Enhancement in Surface-Enhanced Raman Scattering. ACS Nano, 5, 9799-9806. http://dx.doi.org/10.1021/nn204156n

[20] Gao, W., Wu, G., Janicke, M.T., Cullen, D.A., Mukundan, R., Baldwin, J.K., Zelenay, P., et al. (2014) Ozonated Graphene Oxide Film as a Proton-Exchange Membrane. Angewandte Chemie International Edition, 53, 3588-3593. http://dx.doi.org/10.1002/anie.201310908

[21] Cheng, Y.C., Kaloni, T.P., Zhu, Z.Y. and Schwingenschlogl, U. (2012) Oxidation of Graphene in Ozone under Ultraviolet Light. Applied Physics Letters, 101, Article ID: 073110. http://dx.doi.org/10.1063/1.4746261

[22] Zhao, S., Surwade, S.P., Li, Z. and Liu, H. (2012) Photochemical Oxidation of CVD-Grown Single Layer Graphene. Nanotechnology, 23, Article ID: 355703. http://dx.doi.org/10.1088/0957-4484/23/35/355703

[23] Raizer, Y.P., Shneider, M.N. and Yatsenko, N.A. (1995) Radio-Frequency Capacitive Discharges. CRC Press, Boca Raton. 
[24] Volotskova, O., Levchenko, I., Shashurin, A., Raitses, Y., Ostrikov, K. and Keidar, M. (2010) Single-Step Synthesis and Magnetic Separation of Graphene and Carbon Nanotubes in Arc Discharge Plasmas. Nanoscale, 2, 2281-2285. http://dx.doi.org/10.1039/c0nr00416b

[25] Tuinstra, F. and Koenig, J.L. (1970) Raman Spectrum of Graphite. The Journal of Chemical Physics, 53, $1126-1130$. http://dx.doi.org/10.1063/1.1674108

[26] Malard, L.M., Pimenta, M.A., Dresselhaus, G. and Dresselhaus, M.S. (2009) Raman Spectroscopy in Graphene. Physics Reports, 473, 51-87. http://dx.doi.org/10.1016/j.physrep.2009.02.003

[27] Ferrari, A.C., Meyer, J.C., Scardaci, V., Casiraghi, C., Lazzeri, M., Mauri, F., Geim, A.K., et al. (2006) Raman Spectrum of Graphene and Graphene Layers. Physical Review Letters, 97, Article ID: 187401. http://dx.doi.org/10.1103/PhysRevLett.97.187401

[28] Baraket, M., Walton, S.G., Lock, E.H., Robinson, J.T. and Perkins, F.K. (2010) The Functionalization of Graphene Using Electron-Beam Generated Plasmas. Applied Physics Letters, 96, Article ID: 231501. http://dx.doi.org/10.1063/1.3436556 
Scientific Research Publishing (SCIRP) is one of the largest Open Access journal publishers. It is currently publishing more than 200 open access, online, peer-reviewed journals covering a wide range of academic disciplines. SCIRP serves the worldwide academic communities and contributes to the progress and application of science with its publication.

Other selected journals from SCIRP are listed as below. Submit your manuscript to us via either submit@scirp.org or Online Submission Portal.
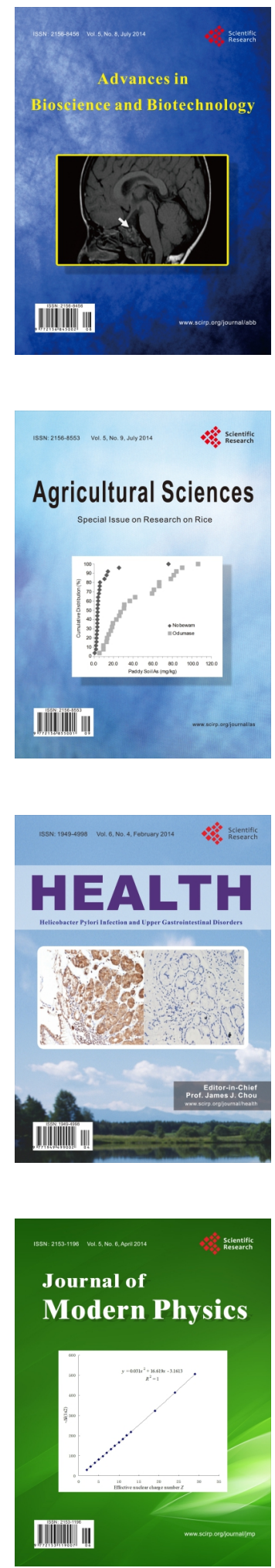
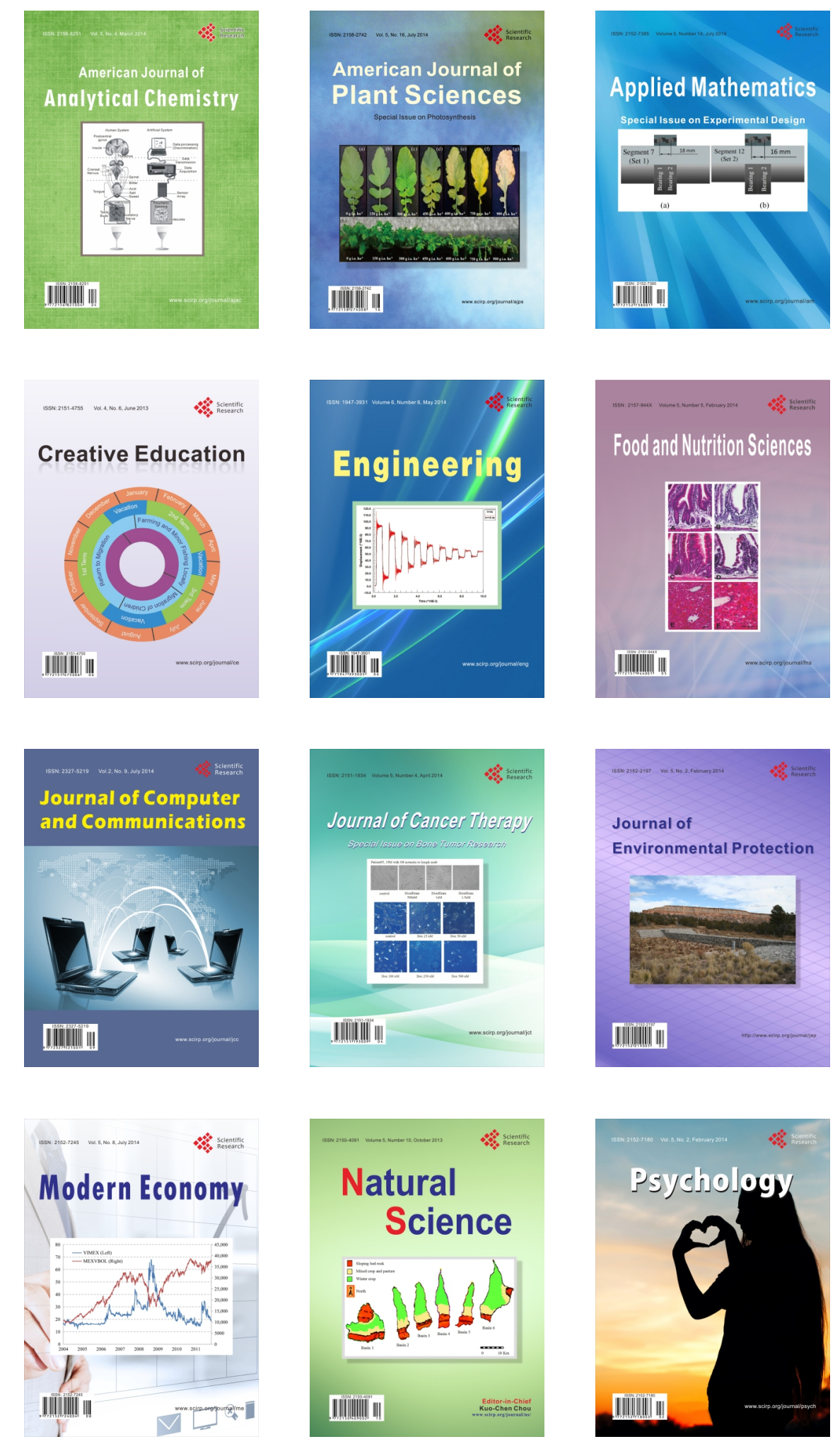